\title{
The interdisciplinary decision problem: Popperian optimism and Kuhnian pessimism in forestry
}

\author{
Johannes Persson $^{1}, \underline{\text { Henrik Thorén }}^{2,3}$ and Lennart Olsson ${ }^{3}$
}

\begin{abstract}
Interdisciplinary research in the fields of forestry and sustainability studies often encounters seemingly incompatible ontological assumptions deriving from natural and social sciences. The perceived incompatibilities might emerge from the epistemological and ontological claims of the theories or models directly employed in the interdisciplinary collaboration, or they might be created by other epistemological and ontological assumptions that these interdisciplinary researchers find no reason to question. In this paper we discuss the benefits and risks of two possible approaches, Popperian optimism and Kuhnian pessimism, to interdisciplinary knowledge integration where epistemological and ontological differences between the sciences involved can be expected.
\end{abstract}

Key Words: forestry; interdisciplinary integration; ontology; philosophy of interdisciplinarity; silviculture; sustainability

\section{INTRODUCTION}

It is sometimes claimed that a central challenge for interdisciplinary sciences, such as sustainability research and forest science, which aim to integrate natural and social dimensions, arises from the apparently incompatible ontological and epistemological assumptions made by natural and social scientists: "Differences in ontology and epistemology constitute one of the main obstacles to the integration of knowledge across scientific disciplines." (Jerneck et al. 2011:78)

The notion that ontological and epistemological differences are a barrier to integration in sustainability science and forestry has an initial plausibility. A contrast that comes to mind here is that between strong and weak sustainability, a contrast some see as one between distinct paradigms (e.g., Neumayer 2013). We believe that, with careful scrutiny, this alleged barrier has the potential to deepen our understanding of the interdisciplinary challenge. In order to obtain this deeper understanding it is necessary, of course, to isolate the supposed barrier and separate it from others. For instance, the politics of science can pose serious problems for interdisciplinarity independently of the epistemological and ontological dimensions we are interested in here (e.g., Lenoir 1997). In what follows, we identify a fundamental type of interdisciplinary decision problem, one that is epistemological and ontological in nature. We begin by presenting possible, and perhaps extreme, responses to the problem. These responses have science-theoretic motivations and origins. After that, we examine the extent to which the interdisciplinary decision problem might highlight particular challenges in interdisciplinary forest science, a strong research field in need of models that enable us to understand the interdisciplinary challenges created by differing ontologies and epistemologies.

\section{THE POPPERIAN OPTIMIST AND THE KUHNIAN PESSIMIST}

The first standpoint is that of the optimist. Optimists may be willing to agree that some collaborations are impeded by ontological and/or epistemological differences between the two or more sciences involved in the relevant interdisciplinary investigation, but they will insist that such differences are relatively superficial and possible to handle.
Somewhat surprisingly, perhaps, Karl Popper is a prime example of this kind of optimism. As far as we know, Popper did not pay much attention to interdisciplinarity and its challenges; he thought in more general terms. For this reason, we need to be careful when labelling him an optimist. The Popperian position is nicely illustrated by the following passage:

Disciplines are distinguished partly for historical reasons
and reasons of administrative convenience (such as the
organisation of teaching and appointments), and partly
because the theories which we construct to solve our
problems have a tendency to grow into unified systems.
But all this classification and distinction is a
comparatively unimportant and superficial affair. We are
not students of some subject matter but students of
problems. And problems may cut right across the borders
of any subject matter or discipline. (Popper 1963:88)

The Popperian optimist hardly discerns a difference between interdisciplinarity and disciplinarity; all science proper is inherently open to other disciplines. Scientific progress happens in science as a whole and is not connected to particular disciplines in anything but the most superficial way. The stakes are low, comparatively speaking, because interdisciplinarity is strictly speaking not a departure from the regular order. Disciplines can perhaps hinder integration on this account, but only for practical reasons, or, say, as a result of the epistemological and/or ontological dogmatism of individual scientists.

The second standpoint is the pessimist's. Here it is useful to draw on another familiar representative from the annals of the philosophy of science, and someone who took a notoriously contrarian view of Popper's views: Thomas Kuhn. Again, as far as we know Kuhn paid little attention to interdisciplinarity and its challenges, so again we need to be cautious when we refer to Kuhnian pessimism.

Kuhn is known for his claim that mature sciences develop firm disciplinary matrices that individual researchers cannot depart from without losing their academic and scientific identity (Kuhn 1977, 1996). These matrices guide the researcher to problems and their solutions. Being a researcher within a mature science involves committing oneself to, among other things, the ontological

${ }^{1}$ Department of Philosophy, Lund University, Sweden, ${ }^{2}$ Helsinki Institute of Sustainability Science, Helsinki University, ${ }^{3}$ Lund University Centre for Sustainability Studies, LUCSUS, Lund University 
assumptions of the science in question. It would be very natural for a Kuhnian to be a pessimist about the possibility of overcoming ontological and epistemological differences between two or more disciplines, and hence about the potential of interdisciplinary research in which such differences might emerge. It is important to note that the difficulty is not primarily social or cultural, even if the researcher and the research community clearly run risks of ending up in a worse situation, after engaging in interdisciplinary collaboration, than they were in before. Fundamentally the epistemological and ontological risks are those of disrupting the discipline or science itself. For Kuhn, disciplines are not passive backdrops to scientific activity and progress; they are the very vehicles in which progress is construed and can take place. Those who seek to reach beyond disciplinary boundaries, then, always help to ensure that there is a considerable risk of undermining progress itself. At any rate, for the Kuhnian pessimist the stakes are enormous in comparison.

It seems to us that there may very well be an inverse relationship between interdisciplinary potential and disciplinary differences in ontology and epistemology. But it also seems plausible to suppose that the exact nature of the relationship depends on whether the optimist or the pessimist is right. If the optimist is right, interdisciplinary potential can survive quite a lot of disciplinary difference. If the pessimist is right, interdisciplinary potential will quickly be destroyed by such disciplinary differences.

\section{THE INTERDISCIPLINARY DECISION PROBLEM}

We shall now formulate what we will refer to as the "interdisciplinary decision problem." We will represent it as a simple $2 \times 2$ matrix with two options and two states. We begin by describing these options and states, and a few of the benefits and risks associated with them.

\section{Options}

Anyone entering an interdisciplinary collaboration might do so in a Kuhnian or a Popperian spirit: he or she might act as if there are fundamental barriers to interdisciplinary integration (Kuhnian pessimism) or not bother about them because they are superficial and can be handled (Popperian optimism).

\section{States}

Which strategy is successful and which is unnecessarily risky, epistemologically and ontologically speaking, will depend on the nature of the disciplines involved and the goods they deliver before integration. The nature of one or both of the sciences, when it comes to epistemology and ontology, might be such that incompatibilities, if they exist, are surface phenomena that would never lead to problematic inconsistencies or ambiguity. Alternatively they might be more Kuhnian, in which case (failure to notice) the introduction of ontological and epistemological inconsistencies might be extremely problematic.

\section{Risks/benefits}

Obviously, the Kuhnian approach will have merit if the sciences involved are Kuhnian in nature and are successful in what they do, but that approach will give rise to a Popperian risk if the sciences are more accurately portrayed in the Popper passage excerpted above (or if they are not successful in what they currently do). The risks and benefits will be unevenly distributed, depending on which of the strategies is taken, if one of the sciences is Kuhnian and the other Popperian. The Popperian risk is that we are not able to solve problems that cut right across the borders of any subject matter or discipline. It is a missed opportunity. Similarly, the Popperian approach is beneficial if the sciences involved have a Popperian nature anyway, but it gives rise to a Kuhnian risk if they are in fact more like the mature science with disciplinary matrices that Kuhn writes about. The Kuhnian risk is that a well-functioning disciplinary matrix is destroyed. We think that the following remarks capture what is at stake in these Kuhnian cases:

\section{The danger of interdisciplinarity, therefore, is to abandon disciplines for a superficial fusing of incompatible frameworks, repressing their elaborate structures that have been created in a painstaking fashion by the collaborative work of generations of scholars. (Burawoy 2013)}

Historical accuracy requires us to note that Kuhn wrote primarily about natural sciences. However, Burawoy's remarks suggest that something very similar to disciplinary matrices, incompatible frameworks with elaborate structure, and hence Kuhnian risks, might exist in the social sciences as well (Fig. 1).

Fig. 1. The interdisciplinary decision problem

\begin{tabular}{lll}
\hline & $\begin{array}{l}\text { Incompatible } \\
\text { epistemologies } \\
\text { and ontologies }\end{array}$ & $\begin{array}{l}\text { Compatible } \\
\text { epistemologies } \\
\text { and ontologies }\end{array}$ \\
\hline $\begin{array}{l}\text { Kuhnian } \\
\text { pessimism: } \\
\begin{array}{l}\text { Perceiving barrier } \\
\text { to integration }\end{array}\end{array}$ & "true positive" & $\begin{array}{l}\text { Popperian risk of } \\
\text { being unable to }\end{array}$ \\
$\begin{array}{l}\text { Popperian } \\
\text { optimism: Not } \\
\text { perceiving barrier } \\
\text { to integration }\end{array}$ & $\begin{array}{l}\text { Kuhnian risk of } \\
\text { destroying a well- } \\
\text { functioning }\end{array}$ & $\begin{array}{l}\text { discipline } \\
\text { problems }\end{array}$ \\
\hline
\end{tabular}

The interdisciplinary decision problem builds on the familiar distinction between Type I and Type II errors. For instance, whereas in science it is important to avoid implying that there is a causal link where there is none (Type I error), for a decision maker it is often more important not to overlook a causal link where there is one (Type II error; cf. Neyman and Pearson 1933). In our case, the Kuhnian risk mimics Type I and the Popperian risk mimics Type II. It makes sense to claim that within the perspective of successful scientific disciplines it is more important to minimize Type I error, i.e., to avoid Kuhnian risks, than it is to minimize Type II error, i.e., to avoid Popperian risks. From the point of view of interdisciplinary science, however, the reverse might typically be true.

The seriousness of Kuhnian and Popperian risks depends, in part, on the risks and benefits associated with integration. It is quite clear that in current science policy discourse integration is highly incentivized, but even if we look beyond integration for the sake of attracting funds, as we must if we want to find out anything about epistemological and ontological consequences, there are clearly substantive benefits to be secured through the successful integration of disciplines (see, e.g., Nissani 1997). 
The point to be made here is that the Kuhnian risk, even where there is no disruption (and thus no complications in previously well-functioning disciplines), is the risk of wasted effort. By contrast, the risk connected with Popperian risk is that of wasted opportunity. But then, depending on the precise types of disciplinary difference and the nature of attempts to integrate the disciplines, other things might be at stake as well. If one counts the reductive and imperialist project of sociobiology as a form of integration, the consequences go far beyond wasted effort (see Dupré 2003). Clarke and Walsh (2009) have argued that one risk associated with imperialism is precisely that of the disruption of an otherwise functioning paradigm resulting in so-called "Kuhnloss" where explanatory power of the displaced paradigm cannot be recovered in the new paradigm. Kuhnian risks thus deserve to be taken seriously.

However, sometimes the disciplines are not very successful in the tasks we want to assign to them. When this happens the perceived negative impact of introducing inconsistencies among the ontological assumptions, as well as other elements that might hamper a well-functioning discipline or science, is not necessarily catastrophic, especially if the resulting framework becomes more powerful in delivering desired outcomes. So, we have to assume that the current state of the art (the state, that is, before integration is attempted) is satisfactory, or promising, so far as the prospect of the Kuhnian risk balancing or outweighing the Popperian risk is concerned. For instance, currently the best way of preparing long-term climate projections uses so-called multimodel ensemble forecasting. Successive projects have sought to integrate current climate models. The latest Intergovernmental Panel on Climate Change (IPCC) report relied on the Climate Model Intercomparison Project Phase 5 (CMIP5). The most recent iteration is CMIP6. The approach is interesting in the present context because the models that are included in this project are not complementary: they do not represent different parts of the climate system. Instead each is a model of the complete climate system. The results that emerge from them are aggregated to produce a single projection. Clearly, there is an ontological issue and a potential Kuhnian risk here. The models make substantively different assumptions about the way the climate system works. And it is not clear that it is possible to integrate them without unearthing ontological inconsistencies. This, however, is not conceived as a barrier to integration; nor is it conceived as a substantial risk in the short run. The ensemble output fits better with available climate data than the outputs of any of the models taken by themselves (Parker 2006). In other words, Kuhnian risks are not on the agenda. This might be because what the IPCC does has no impact on the further development of these models; or it might be because none of the models is thought to harbor the seeds of a new discipline or well-functioning disciplinary matrix.

The benefits of integration are usually cast in epistemic terms. They include things like solving particularly difficult or pressing problems, the promotion of innovation, and a better understanding of the world in general. Better understanding of the ways in which different bodies of scientific knowledge relate to one another, epistemic security, and the unification of science are also among the payoffs that have been mentioned (Sherif and Sherif 1969, Klein 1990, Nissani 1997, Hansson 1999, Thorén and Persson 2013).
A risk one runs when one does not attempt integration is that important insights will be delayed, in the worst-case scenario, indefinitely. So we might put ourselves in an epistemic situation that is objectively worse than what it could have been. Popperian risks are therefore also very important. Hence the interdisciplinary decision problem is not an easy one to address.

\section{THREE EXAMPLES FROM FORESTRY}

The silviculturist/economist and the ecologist in forestry

"Forestry was born out of necessity," the Ministry of Forests, Lands and Natural Resource Operations of British Columbia states in their recent workbook for students and practitioners of silviculture (Introduction to Silvicultural Systems, https://www. for.gov.bc.ca/hfp/training/00014/index.htm). Similar claims have been made about the birth of forest science itself: "There would be ... no forest science without deficiency in wood supplies. This science is only a child of necessity or need" (Cotta 1816, as cited in Puettmann et al. 2009:1).

Reality is of course more complex. Different interests and research areas relevant to forests and forestry have competed with and complemented each other for a long time (for a Swedish perspective, see, e.g., Hagner 2005).

Here we will follow Puettmann and his colleagues (2009) in exploring the more instrumental, industrial, and economical, need for forest science. Growing populations and unregulated exploitation of natural stands of trees in Europe led to severe timber shortages. As early as in 1503 an Act of Parliament referring to the situation in England stated that the forests of the country had been "utterly destroyed" (Holmes 1975). In Norway the total mass volume of timber in forested areas decreased for three centuries between 1600 and 1900 (Aasetre and Bele 2009). Foresters in Europe started to manage stands of trees, and eventually this led to the science of forestry and its interest in silvicultural systems, i.e., planned programs of management during the whole life of a stand designed to achieve specific structural objectives.

With the advent of economic liberalism in the 19th century the idea that the purpose of silviculture was to sustainably maximize profit for landowners became influential. Economical rather than site-level ecological thinking influenced planning through concepts such as that of the normal forest and the Faustmann formula. Central to both concepts were forest management approaches in which forests were divided into similar-sized management units, or simply stands (Puettmann et al. 2009). Stands are defined as groups of trees that foresters can effectively manage as a unit (Nyland 2002). More than any other concept in silviculture, the concept of a stand has since been accepted as a basis, or component, of decision making.

The stand concept can be fed into formal methods used to calculate the value of forestland and assess economically optimal rotation ages. Broadly speaking, it belongs to economics and fits with the kind of ontology developed there.

All of these concepts were used as more than instruments for calculation: they influenced forest management as well. For instance, in the management approaches that often followed from the application of the concepts ideal stands were seen as (1) homogeneous in species mixtures, or monocultures, (2) 
homogenous in size and site conditions, (3) fully stocked, or with homogenous stocking, (4) of homogenous wood quality, (5) organized spatially to facilitate harvesting, and (6) without risks of natural damage and catastrophes (Puettmann et al. 2009). To a degree the concepts changed our forests. However, with a few exceptions silvicultural research plots have been found to be much more uniform than the stands to which the results were expected to apply (Puettmann et al. 2009).

This reminds us of a difference in ontological attitude that is often to be found between students of ecology and students of economics. The ontological claims of working ecologists are often realist: they assume the traditional (Aristotelean) position that theories disclose the world. Students of economics, however, are not afraid to rely on idealization. Silviculturists have sometimes turned idealizations into realities through their management approaches.

Of course, other concepts have at times been very important. For instance, the concept of timber has clearly been central in forestry. "Timber" was the fourth most common word in Journal of Forestry in the period 1902-1912, behind "forest," "trees," and "feet" (Mårald et al. 2016). The concept of timber is not unrelated to that of a stand. If we consider stumpage (the price a private firm pays for the right to harvest timber from a stand), the land expectation value (LEV) is, according to the Faustmann Formula, a function of stumpage price, stand volume, regeneration cost, and interest rate.

There was also early opposition to the idea that the stand concept offered a sound basis for forest management. It was complained, for instance, that the sizes of stands are not based on ecological considerations (see G. H. Mayr, as portrayed in Puettmann et al. 2009).

Perhaps the inclusion of stands would not introduce contradictions in the ontology ecologists assume, but it is far from being a natural component of the ecologist's ontology. Built into forestry, then, from early on were differences between the conceptual tools of silviculture and ecology that might prove difficult to overcome in interdisciplinary collaboration. Klaus Puettmann and colleagues (2009: x) claim that the discipline of silviculture is at a crossroads: "It is very apparent to us that silviculture - and more broadly, forest management - now needs to go through unprecedented changes." This is a clear example of an interdisciplinary field where differences in ontology are brought to the fore, and in their provocative book, Puettmann and colleagues claim that those differences force us to take an interdisciplinary decision of the type we have portrayed in Figure 1. To the extent that we agree with this view, the disciplinary difference between silviculture, with its robust background in economic theory, on the one hand, and ecology, on the other, does seem, potentially, to force the interdisciplinary decision problem on the science of forestry. What is clear to all of us, whether we agree with the Puettmannian analysis or not, is that stand, and related concepts such as site potential, are ontological items in silviculture that clearly do not exist in ecology; and that selection is an ontological item in ecology that does not exist in silviculture. It might be difficult to integrate the two frameworks, even if it is suspected that silviculture has fewer problems in that respect than ecology has.
The question, then, is whether these ontological differences are enough to differentiate between the expected consequences of the Popperian and the Kuhnian approaches to this interdisciplinary decision problem in forest science. Silviculture is perhaps not the kind of discipline or set of activities allowing questions about ontology or epistemology to be easily settled. However, it has no firm disciplinary matrix à la Kuhn. As far as silviculture is concerned, there is arguably no catastrophic Kuhnian risk in sight if we approach interdisciplinary collaboration with Popperian optimism. The Kuhnian risk still exists, but more one-sidedly, for ecologists. Hence, with hindsight, the interdisciplinary decision problem has one preferable solution for silviculturists, but another for ecologists:

1. For silviculturists, it is not rational to act on the assumption that the state "Incompatible epistemologies and ontologies" obtains. Hence there is only one relevant state to consider, namely that the epistemologies and ontologies are compatible. In light of this, Kuhnian pessimism is not warranted; and it has the negative consequence, runs the Popperian risk, of putting us in a position where we cannot solve cross-cutting problems.

2. For ecologists, it is rational to act on the assumption that the state "Incompatible epistemologies and ontologies" obtains. The Kuhnian risk of destroying a well-functioning discipline therefore needs to be considered. Moreover, it has to be weighed against the Popperian risk that we will be unable to solve cross-cutting problems. The preferred way of managing the latter is, of course, to export the problem (as well as the necessary ontological and methodological assumptions to solve it) to forest science.

From both perspectives, the differences could nevertheless be epistemically fundamental because they might affect what students of these topics see when they walk in an old forest:

The old natural forest may have aesthetic appeal to silviculturists, but they do not consider it desirable or productive. It is viewed as an underachiever. [...] Silviculturists typically focus on commercial tree species and whether they are growing up to site potential. They use log and timber grading criteria as a basis to categorize individual trees as being "good" or "bad." (Puettmann et al. 2009:89)

For an ecologist, the same forest is the culmination of hundreds, thousands, or even millions (in the tropics) of years of evolution, adaptation, competition, selection, disturbance, and change. Ecologists marvel at the structural, compositional, and dynamic variability of the forest. (Puettmann et al. 2009:89)

\section{Forest islands}

In parts of West Africa a particular type of landscape can be found in the transition zone between the forests of the south and the savanna of the north: a forest savanna mosaic. One place where this mixture of vegetation dominates is the Kissidougou prefecture in Guinea. James Fairhead and Melissa Leach (1996) describe it as follows:

Kissidougou's landscape is striking. Over open expanses of grassy savanna tower patches of dense, verdant, semi- 
deciduous rainforest. These forest islands, scattered over the gently rolling hills, are generally circular, perhaps a kilometre or two in diameter, and most conceal at their centre one of the prefecture's 800 or so villages. (Fairhead and Leach 1996:1)

Western observers of the region, historically, those associated with the colonial administration, but later those also of scientists and researchers, have tended to assume that the scattered patches of forest are remnants of a once great forest that is being degraded by the (mal-)practices of the indigenous inhabitants of aforementioned villages. The changes, or rather, the apparent changes, were assumed to be "recent, ongoing, unilineal, and essentially anthropogenic in origin" (Fairhead and Leach 1996:53). Such a view would be consistent with the depiction of the European situation presented in the previous section, which assumes that "forestry was born out of necessity."

Fairhead and Leach challenge this perception. They suggest that to the extent that it is useful to enter into such speculation, the natural state of this landscape is not a forest, but a savanna. Interestingly, forest islands often contain, or have at some point in history contained, a settlement of some sort (Fairhead and Leach 1996).

Villagers promote the development of forest islands more or less deliberately in the course of everyday life, occasionally by planting trees, but more often simply by creating fire and soil conditions that favor forest regeneration in savanna. The processes involved can be observed today in the vicinity of recently established settlements (Fairhead and Leach 1996). Supporting Fairhead and Leach, recent studies based on very high resolution remote sensing have reported observations in the Sahel indicating that "villagers safeguard trees on nearby farmlands which contradicts simplistic ideas of a high negative correlation between population density and woody cover" (Brandt et al. 2018:1).

Trees in forest islands are used for timber and protection and can sometimes be seen in the remnants of garden fences that have been left to decay. Where settlements have been abandoned, the forest will often be replaced by savanna. Strikingly, historical records, including aerial photography from 1952 onward and written accounts that go back another 50 or so years, suggest that the landscape of forest islands has not changed much since the first westerners commented on its character.

The shift in perspective is significant for several reasons. The assumption that land degradation is a problem in the region has sometimes led the authorities to punish the (common) use of fire with the death penalty (Fairhead and Leach 1996). It has also aggravated the problem of deforestation. The resulting historical errors about whether, where, and when deforestation has occurred have led to inaccurate accounts of its causes (Fairhead and Leach 1998).

This is a matter of interdisciplinary integration in the following sense: Fairhead and Leach bring knowledge and evidence sourced from different disciplines, anthropology of course, but also historical records, to bear on a particular question, one that previously seemed to be within the purview of forest ecologists. In the light of the application of this integrative perspective on this particular ecosystem (and in effect all ecosystems) ecology as such appears to be threatened.
The example illustrates three points. First, it shows the potential benefits of integration and the impact that it can have on practice down the line. In doing this it illustrates the potential benefits of a Popperian approach to interdisciplinary science. Second, in their approach Fairhead and Leach appear to act as Popperian optimists: they identify several ontological and epistemological differences between natural and social science, and more specifically between anthropology and ecology, but nonetheless proceed to revise conclusions they associate with ecology. This fits well with the idea that they have tackled the interdisciplinary decision problem as Popperian optimists.

The question is whether this version of Popperian optimism has to face the Kuhnian risk. The answer is not entirely clear. As with the previous example, it appears that the Kuhnian risk of disrupting disciplines that are (with the proviso that this is clearly a matter of some contention) functioning is not necessarily borne equally by the parties involved. The discipline most challenged here is ecology, and the effect of the integrative project in the long run is to make ecology a discipline that is in many respects dependent on a range of social and human science disciplines. Fairhead and Leach do explicitly challenge what can be seen as foundational concepts for ecologists, concepts such as nature. And if this challenge is taken seriously, it has far reaching implications for ecology as a discipline. This consequence would be the materialization of the Kuhnian risk, given that the science was functioning well to begin with.

\section{Agroforestry}

Potentially, the interdisciplinary decision problem can also arise between, on the one hand, science and expert communities, and on the other, locals or stakeholders. Anne Jerneck and Lennart Olsson (2013) discuss the slow adoption of agroforestry by subSaharan farmers. They claim that "the ontology of global policies focussing on the merits of agroforestry differs from the ontology of everyday practices and strategies in subsistence agriculture" (Jerneck and Olsson 2013:114). Interestingly, they identify this as a major constraint on the take-up of agroforestry.

Projects launched by development and agroforestry agencies rely on multiple, multiscalar, and long-term views of trees while peasant farmers have multiple yet mainly single-scalar and shortterm views. Experts have a wide perspective locating trees into global-regional-local agro-ecosystems of land management and soil erosion prevention while relating it to poverty-reduction. They stress the intangible benefits from trees such as biodiversity and carbon sequestration indicating the potential of a global public good. In contrast, peasant farmers view trees as local communal or private goods with mainly tangible and immediate services while also carrying intangible symbolic values over generations. To exemplify, Clarence, an old farmer in Kalacha, Kenya defended the cultural value of an old tree threatened by road constructions near his village. To complain, he sent a letter to Jomo Kenyatta, the President at the time. Meanwhile, he persuaded the driver of the bulldozer to save the tree. To this day the tree is still there. It is used for village meetings and keeps its material and symbolic value (Jerneck and Olsson 2013).

Experts and farmers enter into collaboration with different aims and priorities and, at least, to some extent, differing ontologies. These differences lead to problems, Jerneck and Olsson argue, in this case, to difficulties in implementing agroforestry with Kenyan locals who are primarily subsistence farmers. 
Where does this leave us with the disciplinary decision problem, as we have described it above? To begin with, it becomes somewhat less clear that the problem here is one of interdisciplinary integration strictly speaking. It is an ontological barrier, yes, but that barrier is not between disciplines. It is rather between science, or the science-based knowledge of expert communities, and the practical experience or everyday life-worlds of local farmers. Would it be more correct to speak of interdisciplinary integration's intellectual cousin, the transdisciplinary decision problem? There is certainly a strong resemblance to the interdisciplinary decision problem. The practical experience of the farmers harbors ontological ideas and ways of reliably collecting evidence, etc., and these ontological and methodological ideas are in conflict with science. In other words, the interdisciplinary decision problem is not necessarily a problem that presupposes two disciplines. Versions of it might appear as soon as we have two items of somewhat structured and systematically acquired knowledge. This way of looking at the problem would be alien to Kuhn, but not to Popper, who thought that science could have its origin in myth and whatnot.

In other words, in this example the scientists and policy makers seeking to embed desirable practices (agroforestry) among individuals and groups (subsistence farmers) are acting like Popperian optimists. In acting in this way, they either fail to acknowledge the existence of important differences (in perspectives and ontologies) or underestimate their potency. This failure to grasp the ontological and epistemological nuances of the situation explains, at least partly, the difficulties in implementing the practices. Kuhnian pessimism is warranted. There is probably no way to integrate the two knowledge systems in their entirety. Integration presupposes change within the systems to begin with. The expert community needs to harness local knowledge. Practical knowledge systems need tailoring, so that they do not contradict fundamental scientific assumptions. Both might be too demanding to be applied in any specific transdisciplinary encounter, and that is why pessimism is warranted. Over time, however, both processes are essential components of education and science.

\section{TWO REQUIREMENTS ON THE SCRUTINY OF POTENTIAL KUHNIAN RISKS}

We want to emphasize that we fully acknowledge the importance of Kuhnian risks. If scientific progress is to be made over the long term it is important to avoid ontological and epistemological inconsistencies, and a good disciplinary matrix, if one has one, should not be abandoned unless a better alternative is in place. This position, which is familiar and is often advocated in the literature on research programs (Lakatos 1976), is arguably even more attractive when interdisciplinary collaboration is at stake. Those who are active in mature and successful disciplines are typically involved in several interdisciplinary collaborations; they pursue core research in their own fields in addition. It would be strange if failure to solve a problem outside the domain of primary interest in the discipline led to the abandonment of a good disciplinary matrix. It would be more rational, always allowing that whether science ever is rational in this sense is an interesting question, if in such a case the discipline withdrew from the interdisciplinary collaboration and let other disciplines integrate useful elements from it.
Having said that, and without compromising the insight in any way, we want also to emphasize two things. First, certain disciplinary differences, e.g., of the ontological kind, are harmless in the sense that integrating them does not entail inconsistency and leads only to a wider ontological basis. The difference here is readily explained by reconsidering the evolutionary ladder of interdisciplinarity in Jantsch (1972), as adapted in Thorén and Persson (2013; Fig. 2).

Fig. 2. (Part of) Jantsch's (1972) evolutionary ladder of interdisciplinarity, adapted from Thorén and Persson (2013).

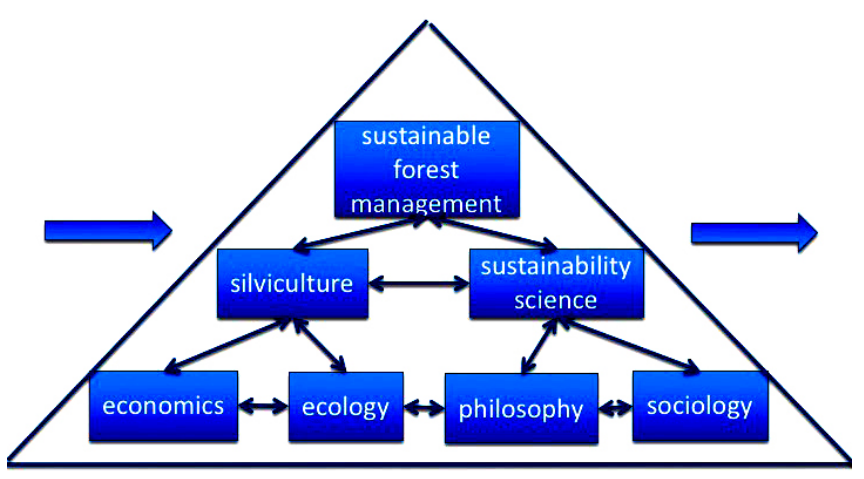

Transdisciplinarity: multilevel coordination by a shared goal

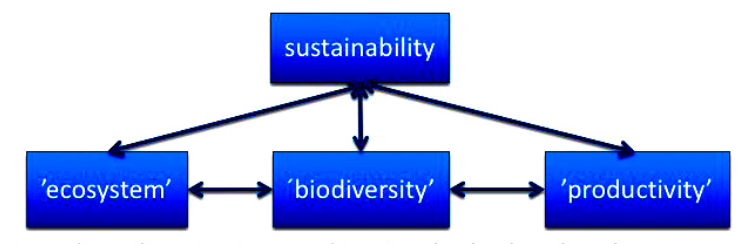

Interdisciplinarity 2: coordination by higher-level concept
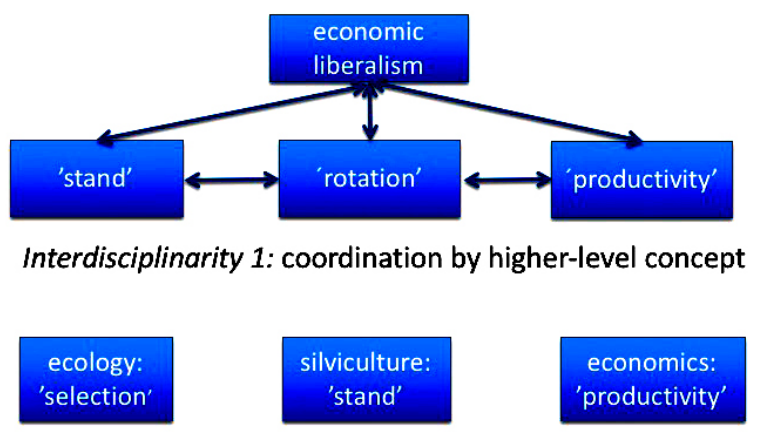

Multidisciplinarity: no coordination

Jantsch's ladder of multidisciplinarity, interdisciplinarity, and transdisciplinarity might also be taken, in our view, to describe a state within a single discipline. Some disciplines seem to consist of rather independent components; others are coordinated in every aspect. To be sure, that variation is exactly what we would expect to see in Popper's view. It may be that in order to have a disciplinary matrix à la Kuhn the relation between the components of the discipline should be more like the ladder rung referred to by Jantsch as transdisciplinarity, although we would not wish to press that point here. Our point is simply that a 
widened basis could be similar to the first rung, multidisciplinarity, and this would not entail inconsistency. As a matter of fact, the comparison might be useful in explaining that certain ontological differences, and other disciplinary differences, pose no problems of interdisciplinary integration. It may also help us to see that integration, somewhat counterintuitively, sometimes entails a transition from a higher rung on the interdisciplinary ladder to a lower, and similarly, within single disciplines. Now, there are reasons why it is sometimes important to work with a small set of ontological building blocks rather than a huge number, but the Kuhnian risk (as we perceive of it) does not explain why that is so. It also appears to us that some of the examples we have discussed here do not give rise to the interdisciplinary decision problem, for exactly this reason.

Second, Kuhnian risk is realized only where interdisciplinary collaboration leads to changes in the ontologies or epistemologies of the disciplines, i.e., where the disciplinary matrices of the disciplines are changed, or even worse, become inconsistent. However, interdisciplinary collaboration can be pursued without this happening. In Thorén and Persson (2013), for instance, it is argued that a powerful way of collaborating in an interdisciplinary way is through problem-feeding. Problem-feeding is a form of interdisciplinary exchange in which the central object of exchange is a problem, or set of problems, rather than, say, a concept, model, or theory. The basic idea is that problems occasionally arise within disciplines in which they cannot be solved easily (see also Sherif and Sherif 1969, Darden and Maull 1977, Maull 1977, Darden 1991). For example, recognition of the seriousness of climate change, which was for a long time the domain of the natural sciences exclusively, has produced a wealth of problems that fall immediately within the purview of the social sciences. How can, and how should, we adapt to climate change? What is the best balance between mitigation and adaptation? What are the limits of adaptation? What are the social drivers of climate change? And so on. As Thorén (2015) has pointed out, problem-feeding may serve to protect the disciplinary matrix by, essentially, exporting an otherwise burdensome anomaly. This involves constraining the domain of the "exporting" discipline, to a degree anyway, but it goes to show that interdisciplinary interaction sometimes serves to reduce intra-disciplinary inconsistencies (perhaps at the expense of leaving interdisciplinary ones).

\section{RISK AND IMPERIALISM}

That there are risks involved in engaging in interdisciplinarity is well-recognized in the literature, although the emphasis is often on professional risks to researchers who engage in research beyond the mainstream of their disciplines, or on the more general uncertainty of outcomes. We have highlighted potentially more substantive risks to the structure of individual disciplines, especially in the form of what we have labeled Kuhnian risks: risks threatening the disruption of a functioning and progressive disciplinary matrix. Typically, Kuhnian risks arise when a discipline either expands into a new domain or incorporates elements from an expanding (other) discipline. They are often the result of imperialism of one form or another (e.g., Dupré 2003, Clarke and Walsh 2009). Recently, the imperialistic tendency of resilience thinking has sometimes led to Kuhnian risks in forestry (e.g., Newton 2016) and sustainability studies (e.g., Olsson et al. 2015). Newton, who is an ecologist, identifies three risks for the conservation of biodiversity in forest ecosystems when resilience is adopted as a policy goal: ambiguity, measurement problems, and misuse of the term.

So, the interdisciplinary decision problem can be seen as a risk management problem. As has been pointed out in connection with some of the examples, and focusing on the disciplines involved, as opposed to the practices that eventually follow, risks and benefits are not always equally distributed among collaborators or, more broadly, involved parties. In Puettmann et al.'s (2009) silviculture case and Fairhead and Leach's (1996) study of forest islands it is the autonomy of ecology as a discipline, and not, say, anthropology or the science or forestry, that faces the primary threat.

Hermansson and Hansson (2007) suggest that in managing decisions that involve risk we need to address important ethical considerations: who is the decision maker, who is exposed to the risk, and who stands to benefit from taking the risk? In certain constellations this becomes especially clear, e.g., when the decision maker and the beneficiary are one and the same individual but the person or group exposed to the risk is someone else. We do not wish to overstrain the analogy, but we note that certain instances of supposed interdisciplinary integration, such as Wilson's (1975) sociobiology, conform, at least superficially, to this pattern. As Mary Midgley (1984) once complained, sociobiology sought to expand the domain of the biological sciences at the expense of the social and behavioral sciences. As a result, the Kuhnian risks were not carried by those who sought integration (and to whom the benefits were most obvious).

But there are limits to this analogy in this context. Clearly disciplines conceived of as research programs can fail, and disciplines do not have exclusive ownership of the domains with which they are associated. Nonetheless, we suspect that keeping an eye on the interdisciplinary decision problem, and on who is bearing the Kuhnian risks in interdisciplinary integration and collaboration, is important, not least when the former is supposed to involve the latter.

\section{CONCLUSION: THE INTERDISCIPLINARY DECISION PROBLEM}

We formulate, perhaps for the first time, a characteristic decision problem that occurs in interdisciplinary settings, and probably in transdisciplinary settings as well: the interdisciplinary decision problem. In order to see it clearly, one has to shield it off from the many, and in the short run more powerful, problems interdisciplinary science encounters. But there is no doubt, we have argued, that the interdisciplinary decision problem is real, and we conjecture that in the long run it is extremely important for scientific progress. In this sense, there is a normative side to the interdisciplinary decision problem. It ought to be taken seriously, and if sustainable scientific progress is to be made, it needs to be taken into account even though, or perhaps precisely because, it is generally overshadowed by the more obvious political, social, and cultural barriers to interdisciplinary science. To be more than a theoretical possibility, the interdisciplinary decision problem-the balancing act between Popperian optimism and Kuhnian pessimism - might of course require something from the politics of science: a certain openness, and perhaps even the kind of open society for which Popper argued. If the interdisciplinary decision problem is to become a real decision problem, and if long-term progress in interdisciplinary 
science is to be a genuine possibility, we may need to avoid being too disciplined by disciplines: interdisciplinary science may not "flourish if science becomes the exclusive possession of a closed set of specialists" (Popper 1995:110).

\section{AUTHOR CONTRIBUTIONS}

J.P. conceived the idea, designed the study, wrote the first draft, and coauthored the final manuscript. H.T. restructured the first draft, contributed ideas, a case probe, and analysis, and coauthored the final manuscript. L.O. contributed ideas to the first draft and the final manuscript, contributed a case probe, and commented on the final manuscript. The authors declare that they have no competing interests.

Responses to this article can be read online at: http://www.ecologyandsociety.org/issues/responses. php/10401

\section{Acknowledgments:}

We are grateful to colleagues in the LUCID consortium, and Alf Hornborg in particular, who contributed with comments on an early draft of this article. Funding: The research has been funded by the following research projects: Swedish Research Council Formas Linnaeus grant LUCID, Lund University Centre of Excellence for integration of Social and Natural Dimensions of Sustainability (259-2008-1718) [to J.P., H.T., and L.O.], and the Swedish Foundation for Humanities and Social Sciences programme VBE, Science and proven experience (M14-0138:1) [to J.P.].

\section{LITERATURE CITED}

Aasetre, J., and B. Bele. 2009. History of forestry in a central Norwegian boreal forest landscape: examples from Nordli, NordTrøndelag. Norsk Geografisk Tidsskrift - Norwegian Journal of Geography 63:233-245. http://dx.doi.org/10.1080/00291950903368342

Brandt, M., K. Rasmussen, P. Hiernaux, S. Herrmann, C. J. Tucker, X. Tong, F. Tian, O. Mertz, L. Kergoat, C. Mbow, J. L. David, K. A. Melocik, M. Dendoncker, C. Vincke, and R. Fensholt. 2018. Reduction of tree cover in West African woodlands and promotion in semi-arid farmlands. Nature Geoscience 11(5):328-333. http://dx.doi.org/10.1038/s41561-018-0092$\underline{x}$

Burawoy, M. 2013. Sociology and interdisciplinarity: the promise and the perils. Philippine Sociological Review 61:7-20.

Clarke, S., and A. Walsh. 2009. Scientific imperialism and the proper relations between the sciences. International Studies in the Philosophy of Science 23(2):195-207. http://dx.doi. org/10.1080/02698590903007170

Darden, L. 1991. Theory change in science: strategies from Mendelian genetics. Oxford University Press, Oxford, UK.

Darden, L., and N. Maull. 1977. Interfield theories. Philosophy of Science 44(1):43-64. http://dx.doi.org/10.1086/288723

Dupré, J. 2003. Human nature and the limits of science. Oxford University Press, Oxford, UK. http://dx.doi.org/10.1093/019924$\underline{8060.001 .0001}$
Fairhead, J., and M. Leach. 1996. Misreading the African landscape: society and ecology in a forest-savanna mosaic. Cambridge University Press, Cambridge, UK. http://dx.doi. org/10.1017/CBO9781139164023

Fairhead, J., and M. Leach. 1998. Reframing deforestation: global analyses and local realities with studies in West Africa. Routledge, London, UK.

Hagner, S. 2005. Skog i förändring: vägen mot ett rationellt och hållbart skogsbruk i Norrland ca 1940-1990. Skogs- och Lantbrukshistoriska meddelanden 34. Kungl. Skogs- och Lantbruksakademien, Stockholm, Sweden.

Hansson, B. 1999. Interdisciplinarity: for what purpose? Policy Sciences 32(4):339-343. http://dx.doi.org/10.1023/A:1004718320735

Hermansson, H., and S. O. Hansson. 2007. A three-party model tool for ethical risk analysis. Risk Management 9(3):129-144. http://dx.doi.org/10.1057/palgrave.rm.8250028

Holmes, G. D. 1975. History of forestry and forest management. Philosophical Transactions of the Royal Society B: Biological Sciences 271(911):69-80. http://dx.doi.org/10.1098/rstb.1975.0035

Jantsch, E. 1972. Towards interdisciplinarity and transdisciplinarity in education and innovation. Pages 97-121 in Interdisciplinarity: problems of teaching and research in universities. Organisation for Economic Co-operation and Development, Paris, France.

Jerneck, A., and L. Olsson. 2013. More than trees! Understanding the agroforestry adoption gap in subsistence agriculture: insights from narrative walks in Kenya. Journal of Rural Studies 32:114-125. http://dx.doi.org/10.1016/j.jrurstud.2013.04.004

Jerneck, A.. L. Olsson, B. Ness, S. Anderberg, M. Baier, E. Clark, T. Hickler, A. Hornborg, A. Kronsell, E. Lövbrand, and J. Persson. 2011. Structuring sustainability science. Sustainability Science 6(1):69-82. http://dx.doi.org/10.1007/s11625-010-0117-x

Klein, J. T. 1990. Interdisciplinarity: history, theory, and practice. Wayne State University Press, Detroit, Michigan, USA.

Kuhn, T. S. 1977. The essential tension: selected studies in scientific tradition and change. University of Chicago Press, Chicago, Illinois, USA.

Kuhn, T. S. 1996/1962. The structure of scientific revolutions. Third edition. University of Chicago Press, Chicago, Illinois, USA. http://dx.doi.org/10.7208/chicago/9780226458106.001.0001

Lakatos, I. 1976. Falsification and the methodology of scientific research programmes. Pages 205-259 in S. G. Harding, editor. Can theories be refuted? D. Reidel, Dordrecht, The Netherlands. http:// dx.doi.org/10.1007/978-94-010-1863-0 14

Lenoir, T. 1997. Instituting science: the cultural production of scientific disciplines. Stanford University Press, Stanford, California, USA.

Mårald, E., N. Langston, A. Sténs, and J. Moen. 2016. Changing ideas in forestry: a comparison of concepts in Swedish and American forestry journals during the early twentieth and twentyfirst centuries. Ambio 45(Suppl. 2):74-86. http://dx.doi. org/10.1007/s13280-015-0744-7 
Maull, N. L. 1977. Unifying science without reduction. Studies in History and Philosophy of Science Part A 8(2):143-162. http:// dx.doi.org/10.1016/0039-3681(77)90012-7

Midgley, M. 1984. Reductivism, fatalism and sociobiology. Journal of Applied Philosophy 1(1):107-114. http://dx.doi. org/10.1111/j.1468-5930.1984.tb00190.x

Neumayer, E. 2013. Weak versus strong sustainability. Fourth edition. Edwin Elgar, Cheltenham, UK. http://dx.doi. org/10.4337/9781781007082

Newton, A. C. 2016. Biodiversity risks of adopting resilience as a policy goal. Conservation Letters 9(5):369-376. http://dx.doi. org/10.1111/conl.12227

Neyman, J., and E. Pearson. 1933. On the problem of the most efficient tests of statistical inference. Biometrica 20A:175-240, 263-294.

Nissani, M. 1997. Ten cheers for interdisciplinarity: the case for interdisciplinary knowledge and research. Social Science Journal 34(2):201-216. http://dx.doi.org/10.1016/S0362-3319(97)90051-3

Nyland, R. D. 2002. Silviculture: concepts and applications. Second edition. McGraw-Hill, New York, New York, USA.

Olsson, L., A. Jerneck, H. Thorén, J. Persson, and D. O'Byrne. 2015. Why resilience is unappealing to social science: theoretical and empirical investigations of the scientific use of resilience. Science Advances 1(4):e1400217. http://dx.doi.org/10.1126/ sciadv. 1400217

Parker, W. S. 2006. Understanding pluralism in climate modeling. Foundations of Science 11(4):349-368. http://dx.doi.org/10.1007/ s10699-005-3196-X

Popper, K. 1963. Conjectures and refutations: the growth of scientific knowledge. Routledge \& Kegan Paul, London, UK.

Popper, K. 1995. The myth of the framework: in defence of science andrationality. M. A. Nottorno, editor. Routledge, London, UK.

Puettmann, K. J., D. K. Coates, and C. Messier. 2009. A critique of silviculture. Island Press, Washington, D.C., USA.

Sherif, M., and C. W. Sherif. 1969. Interdisciplinary coordination as validity check: retrospect and prospects. Chapter 1 in $\mathrm{M}$. Sherif and $\mathrm{C}$. W. Sherif, editors. Interdisciplinary relationships in the social sciences. Aldine Transaction, New Brunswick, New Jersey, USA.

Thorén, H. 2015. The hammer and the nail Dissertation. Lund University, Lund, Sweden.

Thorén, H., and J. Persson. 2013. The philosophy of interdisciplinarity: sustainability science and problem-feeding. Journal for General Philosophy of Science 44(2):337-355. http:// dx.doi.org/10.1007/s10838-013-9233-5

Wilson, E. O. 1975. Sociobiology: the new synthesis. Harvard University Press, Cambridge, Massachusetts, USA. 